\title{
Oligodendrocyte Progenitor Enrichment in the Connexin32 Null-Mutant Mouse
}

\author{
Lysanne Melanson-Drapeau, ${ }^{1}$ Sandy Beyko, ${ }^{1}$ Shefali Davé, ${ }^{1}$ Andrea L. 0. Hebb, ${ }^{1}$ Doug J. Franks, ${ }^{2}$ Caterina Sellitto, ${ }^{3}$ \\ David L. Paul, ${ }^{3}$ and Steffany A. L. Bennett ${ }^{1}$ \\ ${ }^{1}$ Neural Regeneration Laboratory, Department of Biochemistry, Microbiology, and Immunology and ${ }^{2}$ Department of Pathology, University of Ottawa, \\ Ottawa, Ontario, K1H 8M5 Canada, and ${ }^{3}$ Department of Neurobiology, Harvard Medical School, Boston, Massachusetts 02115
}

\begin{abstract}
Before the establishment of chemical synapses, neural progenitors are often coupled by connexin-mediated gap junctions providing a robust mechanism for cell- cell communication in developing brain. The present study was undertaken to determine whether alterations in junctional coupling also affect neural progenitor proliferation, survival, and differentiation in adult brain. We localized the connexin 32 gap junction protein to a subset of NG2+ and platelet-derived growth factor $\alpha$ receptor + early oligodendrocyte progenitors in the dentate gyrus of adult mice. In connexin32-deficient mice, we found an increase in the total number of proliferating nestin + and NG2+ progenitors in the subgranular zone, hilus, and polymorphonuclear layer of the dentate gyrus in vivo and in the total number of nestin + progenitors capable of clonogenic expansion in vitro. By bromodeoxyuridine labeling, lineage analysis, and terminal deoxynucleotidyl nick end labeling, we demonstrate that turnover of these cells is constitutively enhanced in the connexin 32 knock-out dentate gyrus reflecting a dynamic defect in oligodendrogenesis in this population. Analyses of surviving bromodeoxyuridine-labeled cells at 1,3,7, and $28 \mathrm{~d}$ after injection demonstrate that this transient amplifying population fails to terminally differentiate and is deleted by an apoptoticlike mechanism within $3 \mathrm{~d}$ of labeling. These data provide empirical evidence to support the hypothesis that connexin expression influences adult progenitor number and specifically implicate connexin32-mediated signaling in the activation, survival, and differentiation of a subset of early oligodendrocyte progenitors in postnatal brain.
\end{abstract}

Key words: connexin; knock-out; stem cell; gap junction; progenitor; connexin32

\section{Introduction}

The adult mammalian brain contains stem and progenitor cells with the capacity for self-renewal and the ability to differentiate into functional neurons and glia (Gage, 2000). The largest populations are found in the subventricular zone (SVZ) of the lateral ventricle and the subgranular zone (SGZ) of the dentate gyrus (Gage, 2000). There is growing evidence indicating that passage of ions, metabolites, and second messengers between cells via connexin-mediated gap junctions alters neural progenitor fate (Nadarajah et al., 1998; Rozental et al., 1998, 2000; Bittman and LoTurco, 1999; Mercier and Hatton, 2001). Gap junctional intercellular communication (GJIC) is implicated in coordinating neural precursor activation, thereby influencing regional specification, axonal growth, axonal guidance, and synaptogenesis during CNS development (Guthrie and Gilula, 1989; Lo Turco and Kriegstein, 1991; Fulton, 1995; Yuste et al., 1995). In vitro, pharmacological inhibition of GJIC decreases the percentage of embryonic progenitors that enter S-phase and inhibits terminal dif-

\footnotetext{
Received October 8, 2002; revised December 11, 2002; accepted December 12, 2002.

This work was supported by grants from Aventis Pharmaceuticals to D.L.P. and S.A.L.B., the Natural Sciences and Engineering Research Council of Canada (NSERC) to S.A.L.B., and a Premier's Research Excellence Award to S.A.L.B. S.A.L.B. is an Ontario Mental Health Foundation Intermediate Investigator. L.M.D. is supported by an NSERC studentship. S.D. is supported by an NSERC undergraduate studentship. We thank Dr. Klaus Willecke for providing connexin32 knock-out breeding pairs and Jim Bennett for excellent technical assistance.

Correspondence should be addressed to Dr. Steffany Bennett, Neural Regeneration Laboratory, Department of Biochemistry, Microbiology, and Immunology, University of Ottawa, 451 Smyth Road, Ottawa, Ontario, Canada K1H 8M5. E-mail: sbennet@uottawa.ca.

C. Sellitto's present address: Department of Physiology and Biophysics, State University of New York at Stony Brook, Stony Brook, NY 11794-8661.

Copyright $\odot 2003$ Society for Neuroscience $\quad 0270-6474 / 03 / 231759-10 \$ 15.00 / 0$
}

ferentiation of embryonic carcinoma cells into neurons and glia (Bittman et al., 1997; Bani-Yaghoub et al., 1999).

Gap junctions are collections of intercellular channels that provide a direct connection between the cytoplasm of adjacent cells, allowing passage of molecules $<1 \mathrm{kDa}$ in size. The structural subunits of these channels are a highly related family of $>20$ connexin proteins of which at least 11 are expressed in CNS (Willecke et al., 2001). To address whether connexin-mediated communication regulates progenitor fate in adult brain, we began by evaluating glial progenitor activation in connexin32 (Cx32) nullmutant mice. Cx32 protein is first detected between postnatal days 1 and 5 in rodent brain. Expression closely corresponds with the time course of oligodendrocyte maturation (Parnavelas et al., 1983; Dermietzel et al., 1989; Belliveau et al., 1991; Nadarajah et al., 1997). In adults, Cx32 is predominantly expressed in myelinating glia (oligodendrocytes and Schwann cells) of CNS and peripheral nervous system (Parnavelas et al., 1983; Scherer et al., 1995; Dermietzel et al., 1997; Li et al., 1997; Pastor et al., 1998; Altevogt et al., 2002). The significance of Schwann cell expression is underscored by the fact that $\mathrm{C} \times 32$ mutation results in a demyelinating peripheral neuropathy called X-linked Charcot-MarieTooth disease (CMTX) (Bergoffen et al., 1993; Bruzzone et al., 1994). Mild dysmyelination is also observed in the CNS of Cx32 knock-out (Cx32KO) mice (Sutor et al., 2000), and presumably is responsible for the subclinical abnormalities in visual, acoustic, and motor pathways detected in some CMTX patients (Bahr et al., 1999). Together, these data implicate Cx32 in oligodendrocyte maturation. However, the timing of Cx32 expression in differentiating oligodendrocyte progenitors has yet to be evaluated. 
In this study, we demonstrate that $\mathrm{Cx} 32$ protein is expressed by early oligodendrocyte progenitors in the dentate gyrus of adult mice. In Cx32-deficient mice, we find a 50\% increase in the number of bromodeoxyuridine (BrdU)-labeled cells in the dentate gyrus. By lineage analysis and apoptotic assessment, we demonstrate that, in the absence of Cx32, turnover of these cells is constitutively enhanced. BrdU-labeled progeny fail to differentiate and are apparently deleted through an apoptotic-like mechanism within $3 \mathrm{~d}$ of labeling. These results implicate Cx32 in the activation, survival, and differentiation of a specific subset of early oligodendrocyte progenitors.

\section{Materials and Methods}

Generation of KO mice. Breeding pairs of Cx32-deficient mice were obtained from Dr. Klaus Willecke (Universitat Bonn, Germany) (Nelles et al., 1996). To insure uniformity in genetic background, animals were backcrossed to C57BL/6 wild-type (WT) (Charles River Laboratories, Wilmington, DE) for 12 generations.

Histology and lineage analyses. A total of $n=46 \mathrm{Cx} 32 \mathrm{KO}$ and $n=46$ WT mice were evaluated in this study. Animals were killed by lethal injection with sodium pentobarbital and transcardially perfused with 10 mM PBS (10 mm sodium phosphate and $154 \mathrm{~mm} \mathrm{NaCl}$ ) followed by $3.7 \%$ paraformaldehyde in $10 \mathrm{~mm}$ PBS. For histological analysis, brains were removed and postfixed for $24 \mathrm{hr}$ in this same solution, transferred to 10 mм phosphate buffer, and paraffin-embedded according to standard histological procedure. Serial coronal sections $(4 \mu \mathrm{m})$ were cut on a rotary microtome (Leica Microsystems Inc., Richmond Hill, Ontario, Canada). Sections were stained with Hoechst 33258 ( $2 \mu \mathrm{g} / \mathrm{ml}$; Sigma, St. Louis, MO) or cresyl violet according to standard histological procedure. Cell number was established by counting Hoechst-stained nuclear profiles over three adjacent $4 \mu \mathrm{m}$ sections. These values were averaged to yield a single parameter per animal. Layer thickness was determined by measuring the width of layered cell nuclei in CA1 and CA3c pyramidal cells fields and the superior limb of the dentate gyrus using Image Pro Software version 3.01 on a Nikon E800 microscope equipped for epifluorescence. Three measurements were taken in a $0.1 \mathrm{~mm}^{2}$ field and averaged to yield a single value per animal. Cell identity was determined by immunofluorescence, as described by Bennett et al. (1998). Brains were postfixed for $24 \mathrm{hr}$ in $3.7 \%$ paraformaldehyde in $10 \mathrm{~mm}$ PBS and cryoprotected in $20 \%$ sucrose solution in $10 \mathrm{~mm}$ PBS containing $0.001 \%$ sodium azide. Serial coronal sections $(10 \mu \mathrm{m})$ were cryostat-cut (Leica Microsystems Inc.). Primary antibodies were anti-nestin (1:50; Chemicon, Temecula, CA), anti-NG2 (1:200; Chemicon), anti-platelet derived growth factor $\alpha$ receptor (PDGF $\alpha \mathrm{R} ; 1.5 \mu \mathrm{g} / \mathrm{ml}$, BD Biosciences, Mississauga, Ontario, Canada), anti-A2B5 (1:2; American Type Culture Collection, Manassas, VA), anti-O4 (1:50; Chemicon), anti-galactocerebroside (GalC; 1:50; Sigma), anti-proteolipid protein (PLP; 1:100; Biogenesis, Kingston, NH), Cy3-tagged anti-glial fibrillary acidic protein (GFAP; 1:800; Sigma), and anti-NeuN (1:100; Chemicon). Secondary antibodies were Cy3- or FITCconjugated anti-mouse IgG (1:800; 1:100; Jackson ImmunoResearch, West Grove, PA) or IgM (1:600; Jackson), Cy3-conjugated anti-rat (1:400; Jackson), and Cy3- or FITC-conjugated anti-rabbit (1:600; 1:100; Jackson) IgG as appropriate. Antibodies were diluted in antibody buffer (10 mM PBS, $0.3 \%$ Triton $\mathrm{X}-100$, and $3 \%$ bovine serum albumin). Immunofluorescence was evaluated using OpenLab Software, version 3.08 (Improvision, Lexington, MA) on a Leica DMXRA2 microscope equipped for epifluorescence. All other details were as described by Bennett et al. $(1998,2000)$.

Western blot analyses. Mice were killed by lethal injection with sodium pentobarbital and decapitated. Protein was extracted from $n=2-4$ animals per sample using Trizol reagent (Invitrogen, San Diego, CA). Protein concentration was measured with the Bio-Rad (Mississauga, Ontario, Canada) DC assay kit. Proteins $(30 \mu \mathrm{g})$ were separated by SDSPAGE of 7.5 or $12.5 \%$ gels under reducing conditions and transferred to Immobilon membrane (Amersham-Pharmacia Biotech, Baie d'Urfé, Quebec, Canada). Membranes were blocked in $10 \mathrm{~mm}$ PBS containing $1 \%$ casein. Anti-nestin (1:500; Chemicon), anti-GFAP (1:2000; Sigma), anti-GalC (1:200; Sigma), or anti- $\beta$ tubulin (1:400; Sigma) were diluted in the same solution. Secondary antibodies and tertiary reagents were biotinylated anti-mouse IgG (1:10,000; Sigma) and extravidin peroxidase (1:1000; Sigma) or extravidin alkaline phosphatase (1:300,000; Sigma), or peroxidase-conjugated anti-rabbit IgG (1:5000; Jackson ImmunoResearch). Immunoreactivity was visualized by enhanced chemiluminescence following the protocol provided by the manufacturer (Pierce, Rockford, IL). Where reprobing for $\beta$-tubulin is indicated, membranes were processed colorimetrically using 5-bromo-4-chlorindolyl-phosphate-nitroblue-tetrazolium-chloride Fast tablets (Sigma). All other details are as in Bennett et al. (2000).

BrdU labeling of mitotically active cells. BrdU (50 $\mu \mathrm{g} / \mathrm{gm}$ in sterile 10 mм PBS, pH 7.0) was administered intraperitoneally. Animals received two daily injections ( $4-5 \mathrm{hr}$ apart) over 2 consecutive days and a single injection on the third day. Mice were killed $24 \mathrm{hr}$ after the last injection, and brains were processed as described above. Cryostat-cut sections (10 $\mu \mathrm{m}$ ) were incubated in $2 \mathrm{~N}$ hydrochloric acid for $1 \mathrm{hr}$ and neutralized in $0.1 \mathrm{~m}$ borate buffer, $\mathrm{pH}$ 8.5. BrdU incorporation was detected by immunofluorescence using mouse anti-BrdU (6 $\mu \mathrm{g} / \mathrm{ml}$; Roche) and Cy3conjugated anti-mouse IgG (1:800; Jackson ImmunoResearch) as described above. Cell number was established by counting Cy3-BrdU+ nuclear profiles over three adjacent $10 \mu \mathrm{m}$ sections between bregma -1.68 and -2.08 in the CA1 and dentate gyrus of the hippocampal formation using the Measurement Module of OpenLab 3.08 software. Counts were performed by three independent investigators. Values were averaged to yield a single parameter per animal. The total area (in square micrometers) of each region was determined using OpenLab $3.08 \mathrm{Mea}-$ surement Module. Data were expressed as the number of BrdU+ cell profiles per $0.1 \mathrm{~mm}^{2}$. Where double-labeling is indicated, a rat monoclonal FITC-conjugated anti-BrdU $(0.5 \mu \mathrm{g} / \mu \mathrm{l}$; Accurate Chemical, Westbury, NY) and anti-NeuN, anti-NG2, or anti-GFAP were used as described above.

Terminal deoxynucleotidyl transferase-mediated dUTP nick end labeling. Dying cells were detected by terminal deoxynucleotidyl transferasemediated biotinylated UTP nick end labeling (TUNEL). Sections were permeabilized by a $15 \mathrm{~min}$ incubation in $0.1 \%$ Triton X-100-0.1\% sodium citrate on ice and a 2 min incubation in ethanol:acetic acid (2:1) on ice. Sections were rinsed for $2 \mathrm{~min}$ in $10 \mathrm{~mm}$ PBS and reacted for $1 \mathrm{hr}$ at $37^{\circ} \mathrm{C}$ with FITC-labeled dUTP in terminal deoxynucleotidyl transferase (TdT) buffer (30 mm Tris-HCl, pH 7.2, 140 mm sodium cacodylate, and $1 \mathrm{~mm}$ cobalt chloride) and TdT according to the protocol provided by the manufacturer (Roche). TUNEL-reacted sections were double-labeled with NG2 as described above. Negative controls included sections incubated with FITC-labeled dUTP in the absence of TdT. The number of TUNEL + cells was determined as described above for BrdU+ cells.

In vitro culture of progenitors from $\mathrm{C} x 32 \mathrm{KO}$ and WT mice. Clonogenic assays were performed essentially as described for embryonic cultures in Williams et al. (1997). Culture modifications to accommodate adult progenitors were as follows. Primary progenitor cultures were prepared from adult WT and Cx32KO mice at 3 months of age. Mice $(n=3$ animals per condition per experiment) were killed by lethal injection with sodium pentobarbital. The hippocampal formation from both hemispheres was dissected in dissection media (10 mM phosphate buffer, $154 \mathrm{~mm} \mathrm{NaCl}, 2 \mathrm{~mm}$ glucose, and $200 \mathrm{U} / \mathrm{ml}$ penicillin streptomycin) and rocked in dissection media on a clinical orbiter until all samples were collected. Tissue was transferred to sterile $15 \mathrm{ml}$ polystyrene tubes containing $3 \mathrm{ml}$ of $10 \mathrm{U} / \mathrm{ml}$ papain (Sigma) in dissection media brought to $\mathrm{pH} 7.0$ with $1 \mathrm{~N} \mathrm{NaOH}$ and passed repeatedly through a $5 \mathrm{ml}$ pipette. We added $0.05 \%$ trypsin- $0.53 \mathrm{~mm}$ EDTA ( $3 \mathrm{ml}, 1 \times$; Invitrogen), and tubes were rotated at $37^{\circ} \mathrm{C}$ for $10 \mathrm{~min}$. We added $0.5 \%$ trypsin-5.3 mm EDTA $(2.5 \mathrm{ml}, 10 \times$; Invitrogen $)$ to each suspension, and tubes were rotated at room temperature for an additional $10 \mathrm{~min}$. Nine milliliters of plating media consisting of Neurobasal Media with B27 supplement (100 U/ml), $10 \%$ heat-inactivated fetal calf serum, $10 \%$ heat-inactivated horse serum, and $100 \mathrm{U} / \mathrm{ml}$ penicillin-streptomycin (Invitrogen) was added to each tube. Suspensions were transferred to sterile $50 \mathrm{ml}$ polypropylene tubes and passed repeatedly through a 10,5 , and $1 \mathrm{ml}$ pipette followed by trituration through a glass bore Pasteur pipette. Cells were centrifuged and resuspended in $20 \mathrm{ml}$ of plating media. Trypan blue hemocytometer counts were performed. Cultures were not plated unless $>95 \%$ of cells excluded the dye after the dissociation procedure. Primary cultures were 
plated at a density of $5 \times 10^{5} /$ cells $\mathrm{ml}$ in 4 well Lab-Tek culture slides ( 1 $\mathrm{ml} /$ well) coated with poly-D-lysine $\left(50 \mu \mathrm{g} / \mathrm{ml}\right.$ in double-distilled $\left.\mathrm{H}_{2} \mathrm{O}\right)$. On the following day, the media was changed to maintenance media consisting of Neurobasal Media with B27 supplement (100 U/ml), penicillin-streptomycin $(100 \mathrm{U} / \mathrm{ml})$, and basic fibroblast growth factor (bFGF; $20 \mathrm{ng} / \mathrm{ml}$, Invitrogen). After $7 \mathrm{~d}$ of cultures, cells were fixed in $3.7 \%$ paraformaldehyde in $10 \mathrm{~mm}$ PBS for $10 \mathrm{~min}$ and immunoreacted as described above with polyclonal anti-enolase (1:10; Calbiochem), Cy3conjugated anti-GFAP (1:80; Sigma), or monoclonal anti-nestin (1:10; Chemicon). Cultures were double-labeled with anti-enolase and antinestin using FITC- and Cy3-conjugated secondaries (1:600 and 1:800; Jackson ImmunoResearch), respectively, as described above. Colonies of more than seven cells were counted. To assess differentiation potential, colonies were treated for $7 \mathrm{~d}$ with bFGF and then exposed for $5 \mathrm{~d}$ to brain derived neurotrophic factor (BDNF; $10 \mathrm{ng} / \mathrm{ml}$; Invitrogen) in Neurobasal Media supplemented with B27 supplement $(100 \mathrm{U} / \mathrm{ml})$ and penicillin-streptomycin $(100 \mathrm{U} / \mathrm{ml})$.

Statistics. Data are presented as the mean \pm SEM. Data were analyzed by one-way ANOVA followed by Tukey post hoc tests to identify conditions that differed significantly from WT control or Student's $t$ tests, as applicable. In each analysis, $\alpha$ was set at $p<0.05$.

\section{Results}

\section{Generation of C57BL/6 Cx32KO and WT mice}

$\mathrm{Cx} 32 \mathrm{KO}$ mice, in a mixed genetic background of 129SVJ1 and C57BL/6 strains, were obtained from Dr. Klaus Willecke (Nelles et al., 1996). Because 129SVJ1 animals exhibit reduced neural progenitor proliferative capacity relative to other strains (Kempermann et al., 1997), we placed the $\mathrm{Cx} 32 \mathrm{KO}$ in a primarily C57BL/6 genetic background by extensive backcrossing. At the F12 generation, a genetically matched inbred WT colony was derived from Cx32 heterozygote matings. Animals used in the present study were either F11-F12 littermates or the progeny of time-matched pregnancies using the $\mathrm{F} 12 \mathrm{C} 57 \mathrm{BL} / 6 \mathrm{Cx} 32 \mathrm{KO}$, and WT colonies.

\section{Expansion of the SGZ in dentate gyrus of $\mathrm{Cx} 32 \mathrm{KO}$ mice}

We evaluated Nissl-stained serial midbrain coronal sections from WT and Cx32KO mice at 3 months of age. No gross midbrain cytoarchitectural abnormality was noted in the KO. However, a closer morphological analysis of the dorsal hippocampal formation revealed a consistent expansion of hyperchromatic cell profiles in the Cx32KO SGZ and hilus of the dentate gyrus (Fig. 1, arrows) and in the CA3c pyramidal layer of the hippocampus (Fig. 1, arrowheads).

\section{Cx32 localizes to oligodendrocytes and oligodendrocyte progenitors in adult WT dentate gyrus}

Because Cx32 expression kinetics closely match the time course of CNS myelination (Parnavelas et al., 1983; Dermietzel et al., 1997; Li et al., 1997), loss of Cx32 could potentially affect the fate of oligodendrocyte progenitors present in the SGZ. To explore this possibility, expression of $\mathrm{Cx} 32$ protein was evaluated by immunofluorescence. As expected, strong immunoreactivity was observed in small irregular diamond-shaped soma (Fig. 2A,B, asterisks) with long processes (Fig. $2 A, B$, small arrows) consistent with the morphology of terminally differentiated oligodendrocytes. Numerous immunoreactive cells with small cell bodies and shorter stellate processes were also detected in the SGZ and polymorphonuclear layer of the dentate gyrus (Fig. 2A,B, arrowheads). Finally, Cx32+ cells with oblong cell bodies were observed in the SGZ (Fig. 2A,B, large arrows). No labeling was detected in the $\mathrm{Cx} 32 \mathrm{KO}$ negative control (Fig. 2C,D).

To evaluate $\mathrm{Cx} 32$ expression in progenitor populations, double immunostaining for $\mathrm{Cx} 32$ and two characteristic markers of
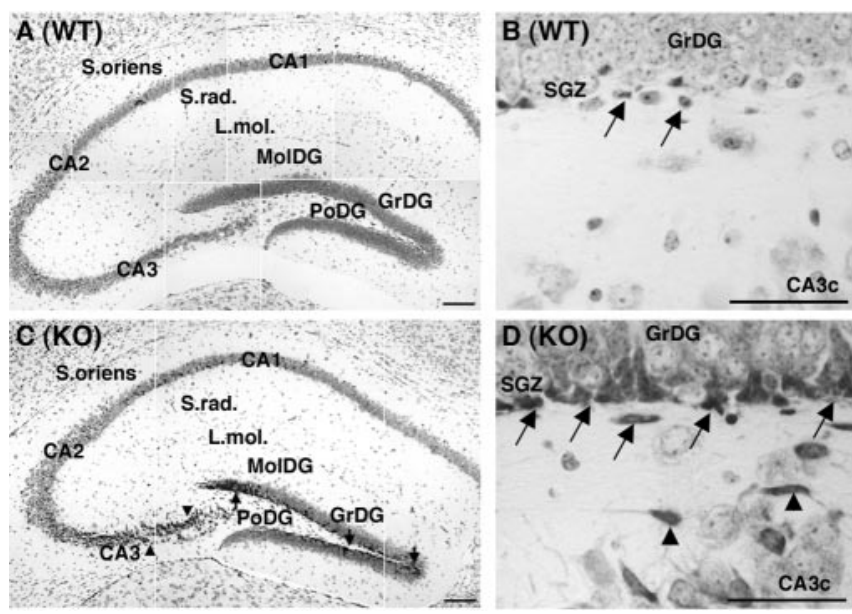

Figure 1. An increase in hyperchromatic cell profiles is detected in the SGZ of the Cx32KO dentate gyrus. CA1,2,3, Pyramidal cell fields of the hippocampus; DG, dentate gyrus; GrDG, granule cell layer of the DG; L. Mol, lacunosum moleculare; MolDG, molecular layer of DG; $P O D G$, polymorphonuclear layer of the DG; $S G Z$, subgranular zone of the $D G ; S$. oriens, stratum oriens; $S$. rad, stratum radiatum. $A, C, A$ sizable population of hyperchromatic Nissl-stained cells was observed in the SGZ and hilus of the DG (arrows) and in the CA3c pyramidal cell layer (arrowheads) of (x32KO mice. Scale bars, $100 \mu \mathrm{m}$. B, D, Morphology of the enriched cell type. Hyperchromatic cells were oblong or oval-shaped in (x32K0 and WT mice (arrows), often with darkly stained short neuritic extensions in (x32K0 animals (arrowheads). Scale bars, $50 \mu \mathrm{m}$.
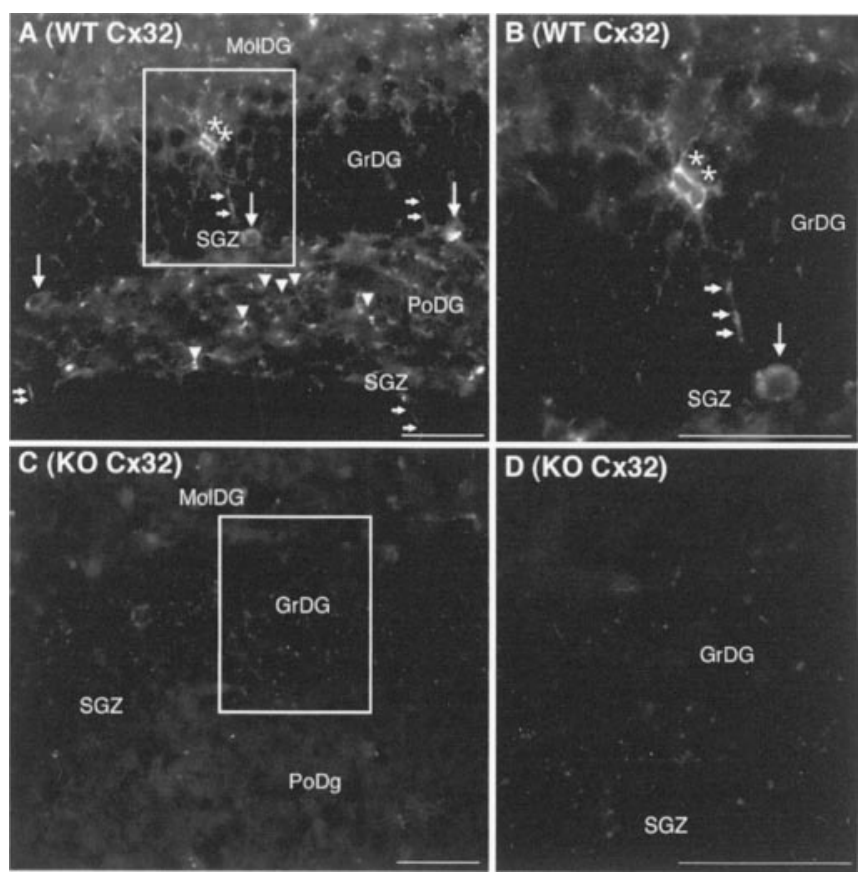

Figure 2. Cx32 localizes to cells with three distinct morphologies in WT dentate gyrus. Abbreviations are as defined in Figure 1. A, Cx32 is detected in cells in the GrDG with diamondshaped soma (asterisks) and long processes (small arrows) typical of oligodendrocytes. Immunoreactive cells with small cell bodies and shorter stellate processes were also observed in the SGZ and PoDG (arrowheads). Larger CX32+ oblong cell bodies were consistently detected in the SGZ (large arrows). $B$, Higher power inset outlined in $A$. $C$, No labeling was detected in the $C \times 32 \mathrm{KO}$ negative control. $D$, Higher power inset outlined in C. Scale bars, $50 \mu \mathrm{m}$.

glial and early oligodendrocyte progenitors: NG2 chondroitin sulfate proteoglycan and PDGF $\alpha$ R (Levine et al., 1993; Dawson et al., 2000; Kondo and Raff, 2000) was performed (Fig. 3). Numerous NG2+ cells with small cell bodies and stellate processes were Cx32+ (Fig. 3A,B, arrows). Punctate Cx32 immunostaining 

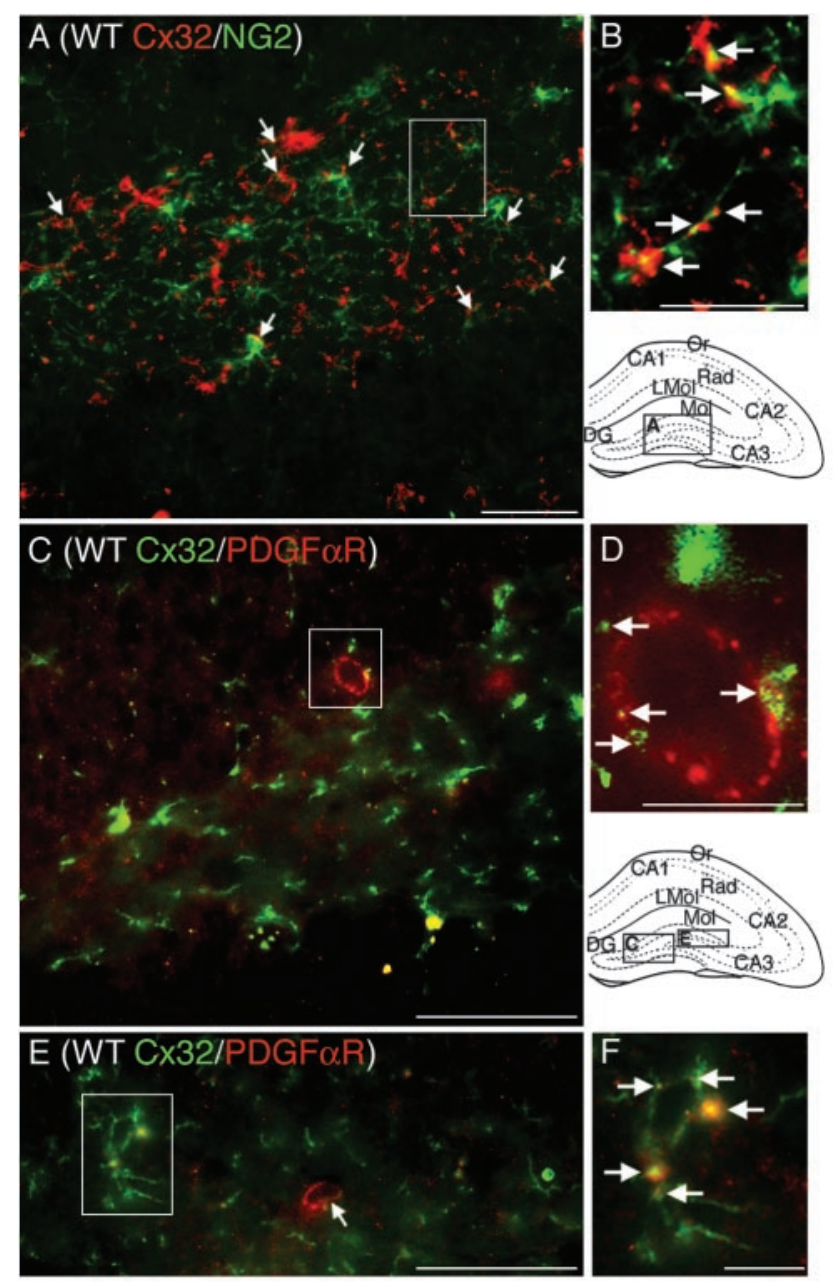

Figure 3. Cx32 localizes to NG2 + and PDGF $\alpha \mathrm{R}+$ oligodendrocyte progenitors in WT dentate gyrus. Abbreviations are as defined in Figure 1. Locations of photomicrographs are indicated in the schematics of the hippocampal formation. $A, C \times 32$ (red) is detected at the plasma membrane of a subset of $\mathrm{NG} 2+$ progenitors (green). $B$, Higher power magnification of inset in A. Arrows indicate $\mathrm{C} \times 32$ labeling on NG2+ processes and cell bodies. C, E, Cx32 (green) is detected at the plasma membrane of PDGF $\alpha \mathrm{R}+$ cells (red) with oblong cell bodies in the SGZ (large arrows). D, F, Higher power magnification of inset in C and $E$. Arrows indicate $C \times 32$ labeling localizing to PDGF $\alpha \mathrm{R}+$ cells. Scale bars: $A, C, E, 50 \mu \mathrm{m} ; B, D, F, 12.5 \mu \mathrm{m}$.

characteristic of gap junctions was also clearly observed at the plasma membrane of larger oblong PDGF $\alpha \mathrm{R}+$ cells in the SGZ (Fig. 3C-F, arrows). Double-labeling with PLP and GFAP determined expression in terminally differentiated glia. Cx32 was not detected in GFAP + astrocytes but was consistently detected in $\mathrm{PLP}+$ oligodendroglia as expected (data not shown).

\section{Cell proliferation is increased in the $\mathrm{Cx} 32 \mathrm{KO}$ dentate gyrus}

To determine whether loss of Cx32 alters proliferation in the SGZ, Cx32KO and WT animals received five intraperitoneal injections of $50 \mu \mathrm{g} / \mathrm{gm}$ BrdU over 3 consecutive days (Fig. 4). Animals were killed $24 \mathrm{hr}$ after the last BrdU injection. A statistically significant increase in the frequency of BrdU+ cells was detected in the $\mathrm{Cx} 32 \mathrm{KO}$ dentate gyrus compared with WT (Fig. 4B). Cx32KO animals exhibited 50\% more BrdU-labeled cells than WT $(p<0.05)$. No difference in BrdU incorporation was observed in the CA1 pyramidal cell field, suggesting that BrdU bioavailability within the hippocampal formation was comparable between $\mathrm{KO}$ and WT groups (Fig. $4 B$ ). The increase in BrdUlabeled cells did not alter overall anatomical size or cytoarchitec- tural organization of the KO dentate gyrus. Total area was comparable between KO and WT (Fig. 4B). Furthermore, the distribution of labeled cells was similar between $\mathrm{Cx} 32 \mathrm{KO}$ and WT mice with the enriched population of $\mathrm{BrdU}+$ cells in the $\mathrm{KO}$ localized primarily to the SGZ and polymorphonuclear layer of the dentate gyrus (Fig. 4C-H).

\section{Progenitor numbers are enhanced in $\mathrm{KO}$ dentate gyrus}

To identify BrdU-labeled cells in Cx32KO mice, expression of nestin, NG2, PDGF $\alpha$ R, A2B5, O4, PLP, GalC, GFAP, and NeuN were evaluated by immunofluorescence. Nestin is a marker of neural, glial, and early oligodendrocyte progenitors (Lendahl et al., 1990; Gallo and Armstrong, 1995). NG2 is expressed by glial and early oligodendrocyte progenitors (Dawson et al., 2000). $\mathrm{PDGF} \alpha \mathrm{R}$ is detected in early oligodendrocyte progenitors (Kondo and Raff, 2000). A2B5 and O4 are expressed by late oligodendrocyte progenitors (Reynolds and Hardy, 1997; Dawson et al., 2000). PLP and GalC label committed oligodendrocytes (Spassky et al., 2001). Increases in nestin (Fig. 5B-E) and NG2 (Fig. 5G,H) immunoreactivity were detected in the SGZ, polymorphonuclear layer, granule cell layer, and hilus of the $\mathrm{Cx} 32 \mathrm{KO}$ dentate gyrus. Elevated nestin protein levels were confirmed by immunoblotting (Fig. 5F). Double-labeling with BrdU demonstrated that more $\mathrm{NG} 2+$ progenitors were actively proliferating in the Cx32KO dentate gyrus than WT (Fig. 5G,H, arrows). Dual immunofluorescence for BrdU and nestin was not possible because the denaturation steps required for BrdU detection markedly reduced nestin immunoreactivity to the point that colocalization could not be reliably assessed. No obvious change in the number, distribution, or proliferative index of $\mathrm{PDGF} \alpha \mathrm{R}+$, $\mathrm{A} 2 \mathrm{~B} 5+, \mathrm{O} 4+, \mathrm{PLP}+$, or GalC + cells was detected. Representative A2B5 immunofluorescence (Fig. 6A,B) and GalC immunoblots (Fig. $6 C$ ) are depicted. There was also no change in the frequency or localization of $\mathrm{NeuN}+$ neurons in the granule cell layer (Fig. $4 \mathrm{C}-\mathrm{H}$ ) or GFAP+ astrocytes in the molecular and polymorphonuclear layers of the dentate gyrus or in the extent of $\mathrm{BrdU}+/ \mathrm{GFAP}+$ double-labeling in $\mathrm{Cx} 32 \mathrm{KO}$ and WT mice (Fig. $6 C-G)$. Together, these data suggest that the loss of Cx32 results in increased proliferation of a subset of nestin + and NG2+ progenitors in adult $\mathrm{Cx} 32 \mathrm{KO}$ dentate gyrus.

\section{Progenitor turnover is enhanced in $\mathrm{Cx} 32 \mathrm{KO}$ mice}

The increase in progenitor number could be attributed to a general increase in neurogenesis during early postnatal development. Thus, the loss of $\mathrm{Cx} 32$ could result in retention of a subset of nestin $+/ \mathrm{NG} 2+$ progenitors over the course of development. According to this hypothesis, adult progenitor fate might not mechanistically depend on Cx32 but rather be a consequence of increased progenitor number at earlier developmental time points. Alternatively, expression of $\mathrm{Cx} 32$ may be actively required for successful commitment of a subset of nestin +/NG2+ progenitors to an oligodendrocyte lineage in adult brain. In the absence of $\mathrm{Cx} 32$ protein, these progenitors would proliferate but fail to terminally differentiate. According to this hypothesis, $\mathrm{Cx} 32$ plays an active role in regulating commitment of specific progenitor populations in adult brain. Clearly, these two hypotheses must be reconciled before the molecular mechanisms underlying $\mathrm{Cx} 32$ mediated progenitor fate can be determined. To address this issue, we evaluated total cell number, layer thickness, cell density, progenitor turnover, progenitor survival, and progenitor differentiation in hippocampi of $\mathrm{Cx} 32 \mathrm{KO}$ and WT mice.

If loss of Cx32 results in a general increase in neurogenesis or gliogenesis over the course of development, then the extra pro- 

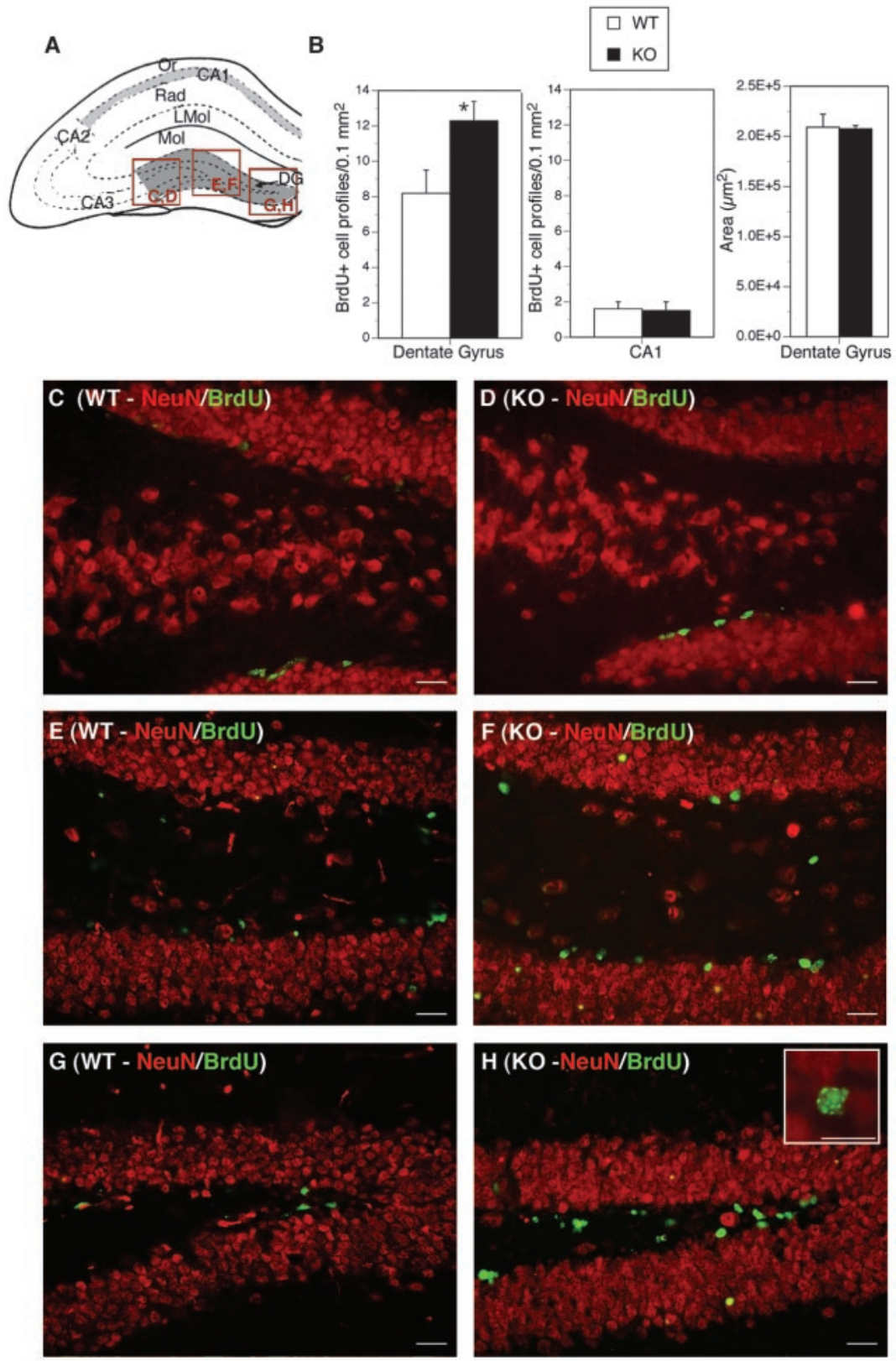

Figure 4. Cell proliferation is increased in the $\mathrm{C} \times 32 \mathrm{~K} 0$ dentate gyrus. Abbreviations are as defined in Figure 1. A, Schematic of the hippocampal formation. The areas chosen for BrdU counts are outlined in dark gray (dentate gyrus) and light gray (CA1 pyramidal field). Locations of photomicrographs $(\mathrm{C}-H)$ are indicated in red. $B$, Quantitation of BrdU + cells in the dentate gyrus and CA1 pyramidal cell field in $n=7$ C $32 \mathrm{KO}$ and $n=10$ WT mice. A statistically significant increase in the number of BrdUlabeled cells was detected in the K0 dentate gyrus (left panel, Student's $t$ test, ${ }^{*} p<0.05$ ), but not in the CA1 cell field (center panel). No difference in the overall area of the dentate gyrus was detected (right panel). $(-H$, Double-labeling for BrdU ( green) and NeuN (red). The increase in BrdU + cells is localized to the SGZ and hilus of the $K 0$ dentate gyrus with some infiltration into the granule cell layer. Proliferating cells in the SGZ and hilus are NeuN-negative. Inset in $H$ depicts a typical pattern of BrdU labeling in KO nuclei. Scale bars, $25 \mu \mathrm{m}$.

genitors would most likely be manifested as an increase in total cell number, layer thickness, or cell density. These parameters were examined in Hoechst 33258-stained sections between bregma -1.68 to bregma -2.08 (Fig. 7). Thicknesses of cell layers in the CA1 field (Fig. 7C,D), CA3c field (Fig. 7E,F), and dentate gyrus (Fig. 7G,H) were comparable between WT and Cx32KO mice. However, in both the CA3c cell field and the dentate gyrus granule cell layer, an increased frequency of small oblong brightly stained nuclei was detected in $\mathrm{Cx} 32 \mathrm{KO}$ animals (Fig. $7 F, H$, arrows). Cell number in the CA3c field was calculated to determine whether these cells increased overall packing density (Fig. 7I). No significant difference in cell number was observed between $\mathrm{Cx} 32 \mathrm{KO}$ and WT mice (Fig. 7I). Furthermore, no obvious differences in the overall cytoarchitecture of the dentate gyrus (Fig. 1), in total area (Fig. $4 B$ ), or in frequency and localization of terminally differentiated $\mathrm{NeuN}+$ neurons (Fig. $4 \mathrm{C}-\mathrm{H}$ ) or GFAP+ astrocytes (Fig. $6 C-G)$ were observed. Thus, the increase in progenitor number and proliferation exhibited by adult $\mathrm{Cx} 32 \mathrm{KO}$ mice is not accompanied by evident increases in cell number or significant changes in developmentally dependent differentiation, migration, or localization of neurons and glia.

Given that the proliferative index of progenitors is enhanced in the Cx32KO SGZ (Figs. 4, 5), but overall cell number remains constant (Fig. 7), TUNEL was performed to determine whether cell death is increased in the $\mathrm{Cx} 32 \mathrm{KO}$ relative to WT. A significant increase in the number of TUNEL + cells was detected in the $\mathrm{Cx} 32 \mathrm{KO}$ dentate gyrus relative to WT $(p<0.05)$ (Fig. $8 A, B, D)$. TUNEL + cells were predominantly NG2+ progenitors (Fig 8C, arrowheads). To establish the kinetics of progenitor survival in adult dentate gyrus, the number of BrdUlabeled cells was assessed 1, 3, 7, and $28 \mathrm{~d}$ after the last BrdU injection (Fig. 9). As reported above, a significant increase in BrdUlabeled cells in the dentate gyrus of $\mathrm{Cx} 32 \mathrm{KO}$ mice was detected $24 \mathrm{hr}$ after injection, compared with WT (Figs. 4B, 9). However, surviving cell number decreased rapidly in Cx32KO dentate gyrus and was comparable with WT within $3 \mathrm{~d}$ of BrdU injection (Fig. 9). Survival of BrdU-labeled cells was significantly reduced $28 \mathrm{~d}$ after injection in both $\mathrm{WT}$ and $\mathrm{Cx} 32 \mathrm{KO}$ dentate gyrus $(p<0.05)$ (Fig. 9). WT mice exhibited a $85 \%$ reduction in BrdU-labeled cell number over the $28 \mathrm{~d}$ survival period; KO mice exhibited a $92 \%$ reduction. Although it is possible that the BrdU label became diluted $72 \mathrm{hr}$ after injection as a result of hyperproliferation, and therefore labeled progeny were not detected, the threefold increase in TUNEL+/NG2+ cells (Fig. 8) in the Cx32KO dentate gyrus and the equivalent overall cell number in Cx32KO and WT hippocampi (Fig. 7) indicate that hyperproliferation is balanced by cell death. Together, these findings suggest that, in the absence of $\mathrm{Cx} 32$, progenitor proliferation is constitutively enhanced in the adult SGZ (Figs. 4, 5) but that the NG2+ progeny are deleted before differentiation (Figs. 8, 9). Deletion occurs through an apoptotic-like mechanism involving nuclear and chromatin condensation (Fig. 7), cytoplasmic condensation, pyknosis, hyperchromaticity (Fig. 1), and DNA fragmentation (Fig. 8) in the absence of significant gliosis (Fig. 6). 


\section{In vitro proliferation and} differentiation of $\mathrm{Cx} 32 \mathrm{KO}$ progenitors Nestin + progenitors are capable of selfrenewal and differentiation into functional neurons and glia in vitro. Because we performed BrdU/NG2 double-labeling in vivo but not nestin/BrdU double-labeling as a result of technical considerations, we were unable to establish definitively whether loss of $\mathrm{Cx} 32$ increases nestin+ progenitor proliferation in adult brain. To confirm nestin + progenitor enrichment in vitro, clonogenic assays were performed on cultured primary hippocampal cells. Cx32KO and WT single cell suspensions were plated on poly-D-lysine-coated dishes, cultured for $7 \mathrm{~d}$ in bFGF, fixed, and double-labeled with anti-nestin (Fig. $10 A, D)$ and anti-enolase (Fig. 10A,E) or anti-nestin and anti-GFAP (data not shown). Colonies of more than seven cells in size were counted. In three separate experiments, the ratio of $\mathrm{Cx} 32 \mathrm{KO}$ colonies to WT was consistently 4:1 or a threefold increase in colony formation (Fig. 10 A, Total). The majority of $\mathrm{Cx} 32 \mathrm{KO}$ colonies were nestin + and enolase- or GFAP-, confirming that they were progenitor cells and not adult neurons or glia (Fig. 10 A,C$E$ ). The nestin +/enolase - cells found in colonies were large phase-dark oblong cells often exhibiting blunt neuritic extensions (Fig. 10C). WT colonies (approximately one colony per well) were nestin - and enolase+ (Fig. 10A) and thus were likely pre-existing adult neurons that had plated in close proximity or progeny of committed progenitors that differentiated within $7 \mathrm{~d}$ of plating. These data indicate that a larger percentage of single cells dissociated from $\mathrm{Cx} 32 \mathrm{KO}$ are nestin + progenitors capable of clonogenic expansion in vitro.

In vivo, the enriched population of progenitors in the Cx32KO SGZ fails to differentiate to oligodendrocytes, given that we do not detect an increase in PDGF $\alpha \mathrm{R}+, \mathrm{A} 2 \mathrm{~B} 5+, \mathrm{GalC}+$, or PLP + cells and instead is rapidly deleted. To definitively establish whether the increased population of proliferating nestin + progenitors can differentiate into lineages other than oligodendrocytes, single cells dissociated from $\mathrm{Cx} 32 \mathrm{KO}$ and WT hippocampi were treated for $7 \mathrm{~d}$ with bFGF to promote clonal expansion and then incubated with BDNF for an additional $5 \mathrm{~d}$ to induce neuronal differentiation (Fig. 10B,F-H). Cultures were double-labeled with anti-nestin (Fig. $10 B, G$ ) and anti-enolase (Fig. $10 B, H$ ). Colonies (more than seven cells) were analyzed. As in Figure $10 \mathrm{~A}$, a threefold increase in colony formation was observed in $\mathrm{Cx} 32 \mathrm{KO}$ cultures relative to $\mathrm{WT}$, consistent with the increased number of nestin + progenitors detected in vivo (Fig. $10 \mathrm{~B}$, Total). Significantly, after BDNF treatment, the majority of $\mathrm{Cx} 32 \mathrm{KO}$ progenitor colonies differentiated into enolase $+/$ nestin - neurons (Fig. 10 B, Total, F-H). Differentiated enolase + cells were phase-bright, with small cell bodies and elaborate neuritic processes (Fig. 10F). These data confirm our in vivo observations that loss of $\mathrm{Cx} 32$ results in ex- pansion of $\mathrm{NG} 2+$ /nestin + early oligodendrocyte progenitors but does not significantly affect the capacity of these cells to differentiate to lineages other than oligodendrocytes.

\section{Discussion}

In this study, we show, for the first time, that Cx32 is expressed by a subset of early oligodendrocyte progenitors in the murine dentate gyrus and that the loss of $\mathrm{Cx} 32$ prevents differentiation of these progenitors to oligodendroglia. In adult C57BL/6 mice, we localized $\mathrm{Cx} 32$ protein to a subpopulation of $\mathrm{NG} 2+/ \mathrm{PDGF} \alpha \mathrm{R}+$ early oligodendrocyte progenitors as well as terminally differentiated populations of oligodendroglia in the dentate gyrus. To determine whether loss of $\mathrm{Cx} 32$ is associated with a defect in adult oligodendrogenesis in the dentate gyrus, we evaluated activation, survival, and differentiation of progenitors in adult $\mathrm{Cx} 32 \mathrm{KO}$ mice. Constitutive loss of $\mathrm{Cx} 32$ protein resulted in an overproliferation of nestin + and NG2 + progenitors. The majority of these progenitors did not survive for extended periods of time given a substantive loss of BrdU label within $3 \mathrm{~d}$ of injection. To establish 

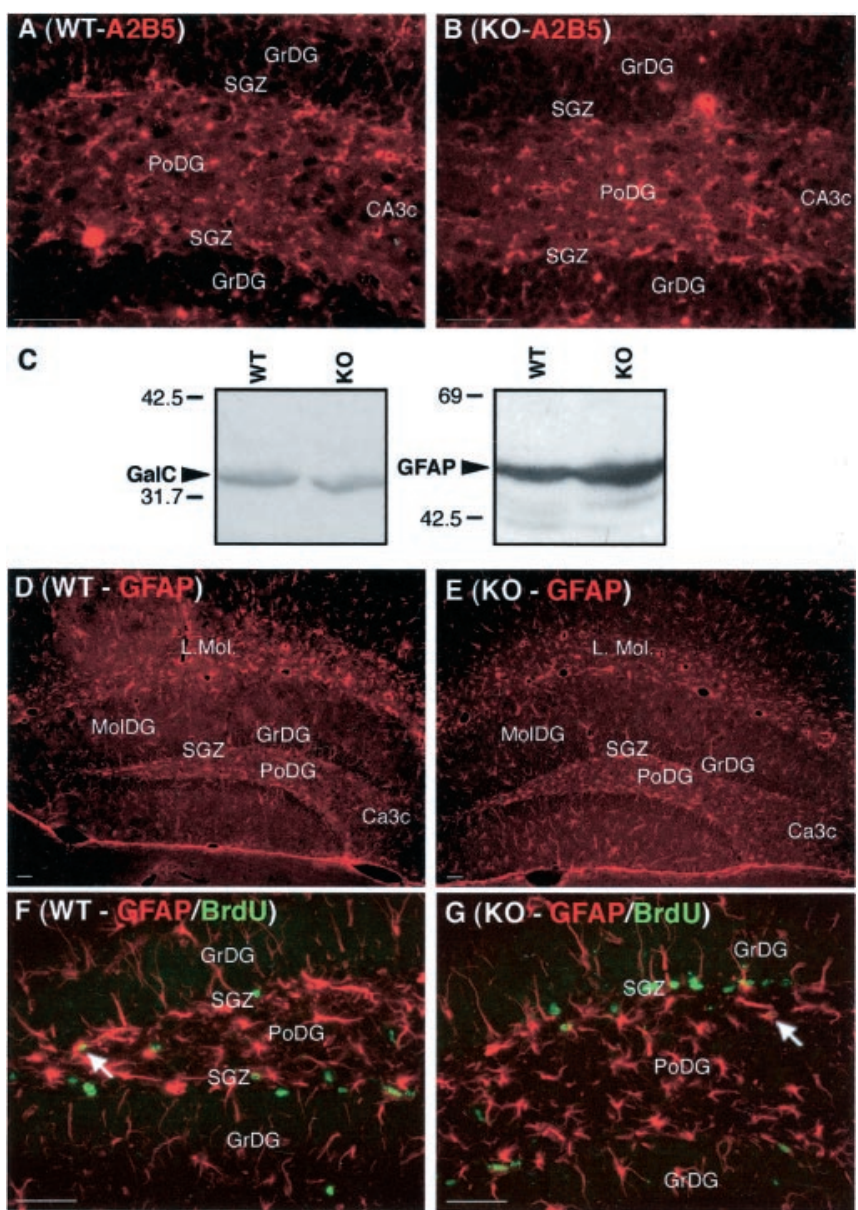

Figure 6. The expanded cell population in the Cx32KO SGZ does not express immunogenic markers of late oligodendrocyte progenitors, terminally differentiated astrocytes, or oligodendrocytes. Abbreviations are as defined in Figure 1. A, B, No significant change in A2B5immunostaining (late oligodendrocyte progenitors) was detected in the dentate gyrus between WT and KO mice. C, Western blot analysis of GalC (oligodendrocytes) and GFAP (astrocytes) demonstrated comparable protein levels between (x32KO and WT. D, E, No change in gliosis was detected between WT and Cx32KO mice. F, G, The majority of BrdU-labeled proliferating cells ( green) in both WT and (x32K0 dentate gyrus were GFAP-negative (red). A small number of cells in both groups were GFAP + (arrows). Scale bars, $50 \mu \mathrm{m}$.

whether the reduction in BrdU labeling resulted from either hyperproliferation and hence label dilution or cell death in the Cx32KO dentate gyrus, we evaluated cell number, layer thickness, and apoptotic index. We did not detect any overall increases in cell number or layer thicknesses in the $\mathrm{Cx} 32 \mathrm{KO}$ relative to the WT. However, a significant increase in the number of TUNEL+ cells localizing predominantly to NG2+ progenitors was observed in Cx32 null-mutant mice. We conclude that, in the absence of Cx32 protein, a subset of NG2+ progenitors fail to terminally differentiate. Proliferation is enhanced constitutively likely in an attempt to compensate for this failure in differentiation, and defective progeny are subsequently deleted through an apoptotic-like mechanism.

Although we cannot definitively distinguish between nestin +/NG2 + glial progenitors or nestin +/NG2+ early oligodendrocyte progenitors, the affected population of cells is likely composed of oligodendrocyte progenitors. Three lines of evidence attest to the competency of neural and glial progenitor populations in the adult Cx32KO. First, no significant differences in the frequencies of GFAP+ terminally differentiated astrocytes and $\mathrm{A} 2 \mathrm{~B} 5+, \mathrm{O} 4+$, or PLP+ oligodendroglia were observed in
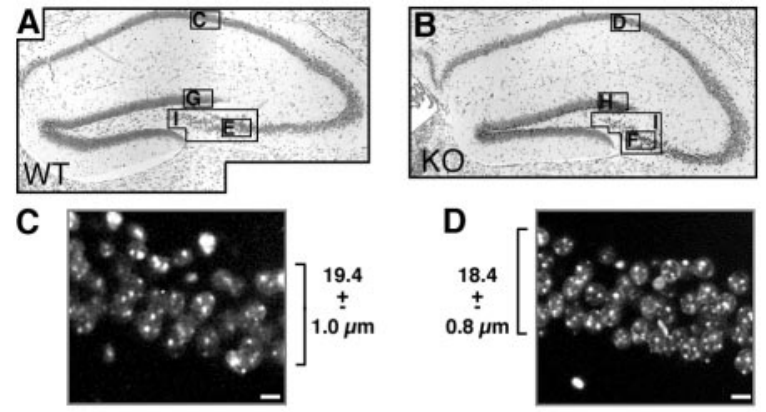

E
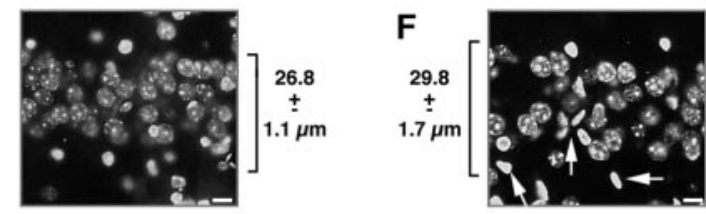

G
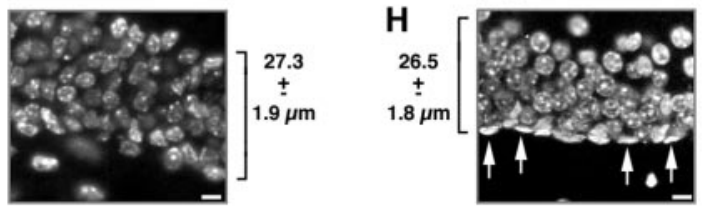

Figure 7. No difference in layer thickness or cell density is detected in the hippocampal formation of Cx32KO and WT mice. A, B, Nissl-stained WT and Cx32KO dorsal hippocampal formation. The areas chosen for nuclear counts and measurements are indicated in the photomicrographs. $\mathrm{C}-\mathrm{H}$, Adjacent sections were stained with Hoechst 33258. Layer thickness was measured in $n=5$ animals per condition. Average layer thickness \pm SEM is indicated beside each photomicrograph. C, WT CA1 cell field. D, KO CA1 cell field. E, WT CA3c cell field. F, KO CA3C cell field. $G$, WT dentate gyrus granule cell field. $H$, KO dentate gyrus granule cell field. Scale bars, $5 \mu \mathrm{m}$. No difference in layer thickness was detected in any of the cell fields. A higher frequency of small oblong brightly stained nuclei was detected in the CA3c pyramidal cell field of the hippocampus and granule cell field of the dentate gyrus in $\mathrm{KO}$ than WT animals ( $F, H$, arrows). $I$, Nuclei in the CA3c pyramidal cell field in three adjacent sections were counted in $n=5$ animals per condition. Values were averaged to yield a single measurement per animal. No significant difference in nuclei number was detected (Student's $t$ test; $p>0.05$ ).

Cx32KO mice, suggesting that the majority of glial and oligodendrocyte progenitors are capable of differentiation. Second, we show that differentiation is blocked and turnover is enhanced in a transiently enriched population of NG2 + cells. Third, our in vitro data demonstrate that the actively proliferating progenitors in the $\mathrm{Cx} 32 \mathrm{KO}$ retain their multipotential capacity to differentiate to neurons. In vivo, no obvious difference in neuron number, neuronal localization, or cytoarchitecture was detected in the Cx32 null-mutant mouse. Together, these findings indicate that, in the absence of $\mathrm{Cx} 32$, multipotential and bipotential progenitors are apparently competent but hyperactive and that null mutation inhibits differentiation of a subset of early oligodendrocyte progenitors.

Alternative explanations for the increase in early oligodendrocyte progenitor number in the $\mathrm{Cx} 32 \mathrm{KO}$ mouse Connexin null-mutant mice represent the best available means of examining the contribution of individual connexins to neuro- 
genesis, gliogenesis, and neural differentiation. Typically, KOs are obtained in a mixed genetic background of 129SVJ1 and C57BL/6 strains. However, 129SVJ1 animals exhibit reduced neural progenitor number relative to other strains (Kempermann et al., 1997) that might obscure the effects of altering connexin levels. To address this issue, we backcrossed extensively to the F12 generation to produce a $\mathrm{Cx} 32 \mathrm{KO}$ in a primarily $\mathrm{C} 57 \mathrm{BL} / 6$ genetic background. Regardless, in both mixed (data not shown) and backcrossed animals, Cx32KOs exhibit more, not less, proliferating progenitors than controls. Because the KO locus is always derived from the 129 background, it seems very unlikely that the enrichment effect is attributable to strain-specific differences in genes closely linked to $\mathrm{Cx} 32$.

The hyperproliferation of progenitors in the $\mathrm{Cx} 32 \mathrm{KO}$ dentate gyrus may also be attributable to a general increase in neurogenesis or gliogenesis during development. Because significant Cx32 expression is not detected in embryonic brain (Parnavelas et al., 1983; Dermietzel et al., 1989; Belliveau et al., 1991; Nadarajah et al., 1997), it is unlikely that mutation would impact on the retention of embryonic progenitor populations. However, the loss of Cx32 during postnatal oligodendrogenesis could potentially result in enhanced survival of $\mathrm{NG} 2+$ progenitors. To address this possibility, we evaluated total cell number, layer thickness, cell density, progenitor turnover, progenitor survival, and progenitor differentiation in hippocampi of our $\mathrm{C} 57 \mathrm{BL} / 6 \mathrm{Cx} 32 \mathrm{KO}$ and WT mice. We did not detect an increase in overall cell number, layer thickness, or cell density, as would be expected if additional progenitor populations were retained over the course of development. Furthermore, our analysis of BrdU-labeled cell survival indicates that constitutive progenitor turnover is a dynamic process in adult brain. Both the proliferation and concomitant apoptotic deletion of cells are markedly enhanced in the adult CX32KO dentate gyrus. Thus, the changes in proliferation and nestin and NG2 immunoreactivity detected in the adult $\mathrm{Cx} 32 \mathrm{KO}$ mouse reflect an ongoing defect in the absence of $\mathrm{Cx} 32$ protein rather than an earlier event in development. It will be important to evaluate whether this defect is site-specific by determining changes in early oligodendrocyte progenitor turnover in other brain regions.

\section{Connexin-mediated control of oligodendrocyte progenitor fate}

Cx32 is a gap junction subunit protein expressed by myelinating cells (oligodendrocytes and Schwann cells) in the CNS and peripheral nervous system. Cx32 mutation results in a demyelinating peripheral neuropathy called X-linked Charcot-Marie-Tooth disease (CMTX) (Bergoffen et al., 1993; Bruzzone et al., 1994). Cx32 null-mutant mice have been shown previously to exhibit deficits in peripheral nerve myelination resulting in reduced
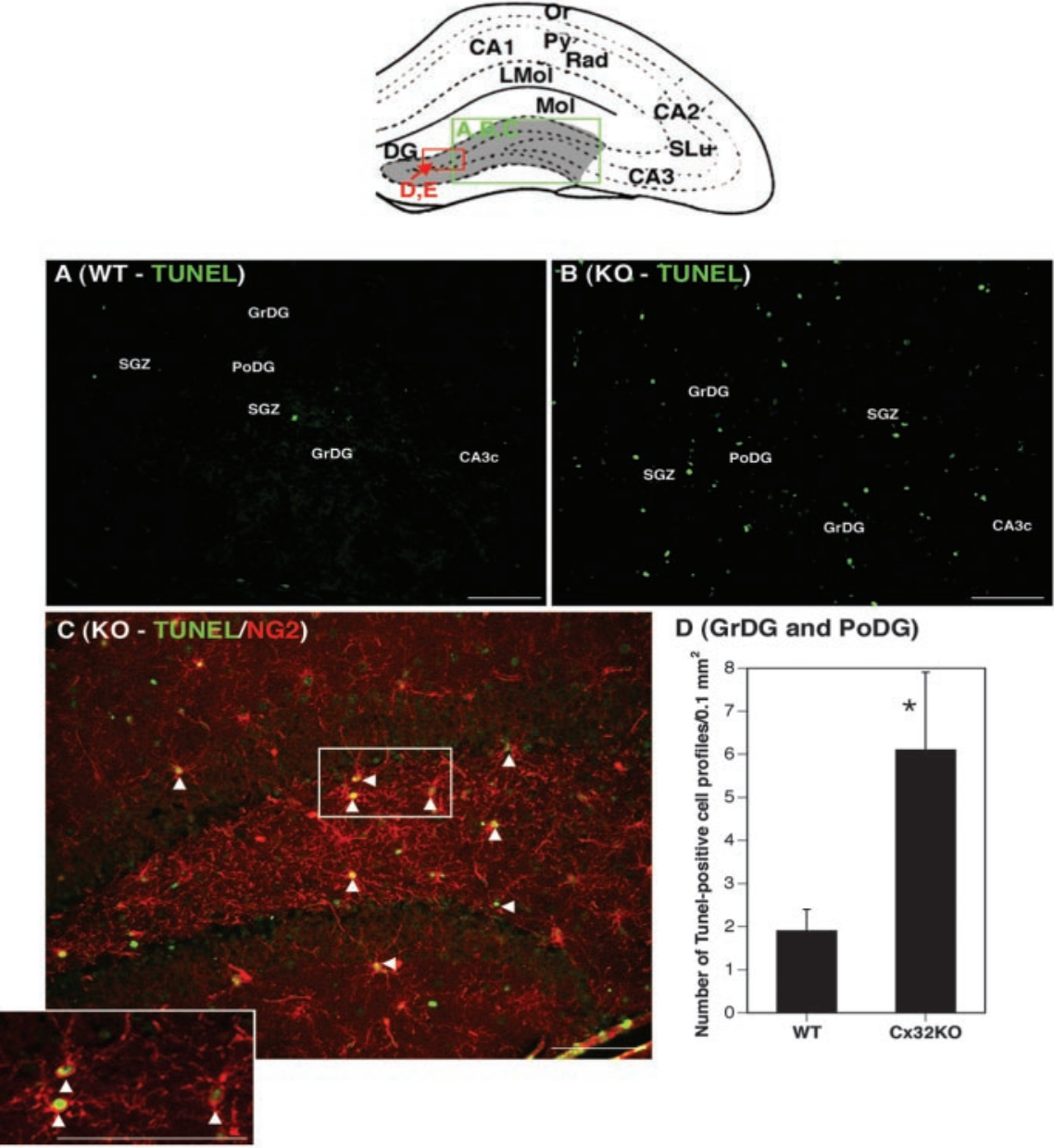

D (GrDG and PoDG)

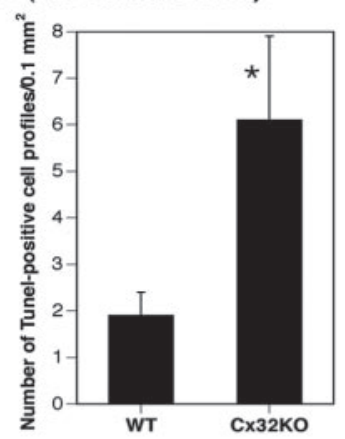

Figure 8. Cell death of $\mathrm{NG} 2+$ progenitors is increased in the $\mathrm{C} \times 32 \mathrm{KO}$ dentate gyrus. Abbreviations are as defined in Figure 1. The location of photomicrographs is represented in the schematic. A, TUNEL labeling of DNA strand breaks in WT animals (green) $B, A n$ increased frequency of TUNEL + cells is consistently detected in Cx32KO dentate gyrus. C, TUNEL + cells ( green) are (red) progenitors (arrowheads). Inset depicts higher magnification of TUNEL +/NG2 + cells. D, Quantitation of imals per group. A statistically significant increase in TUNEL + cells was detected in Cx32K0 mice ( $p \leq 0.05$; Student'st test).

nerve conductance velocity (Anzini et al., 1997; Scherer et al., 1998) and minor defects in CNS myelination (Sutor et al., 2000). Subclinical CNS abnormalities in visual, acoustic, and motor pathways are observed in some CMTX patients (Bahr et al., 1999). Our data add to these well established experimental and clinical studies and extend these observations by localizing Cx32 to a specific subset of oligodendrocyte progenitors. This localization provides a hitherto unexplored explanation for the apparent sparing of CNS myelinating glia in CMTX patients. Our data leave open the possibility that other connexins may also play a role in directing early oligodendrocyte progenitor commitment and differentiation. Three other connexins are expressed by mature oligodendrocytes, Cx29, Cx45, and possibly Cx47, with Cx32 and Cx29 localizing to different subsets of terminally differentiated oligodendroglia (Dermietzel et al., 1997; Sohl et al., 2001; Altevogt et al., 2002). It will be essential to determine whether this cell-specific localization also applies to discrete oligodendrocyte progenitor populations in different brain regions. Connexinspecific expression in distinct populations of early oligodendrocyte progenitors may be responsible for specific defects in CNS myelination after mutation. 


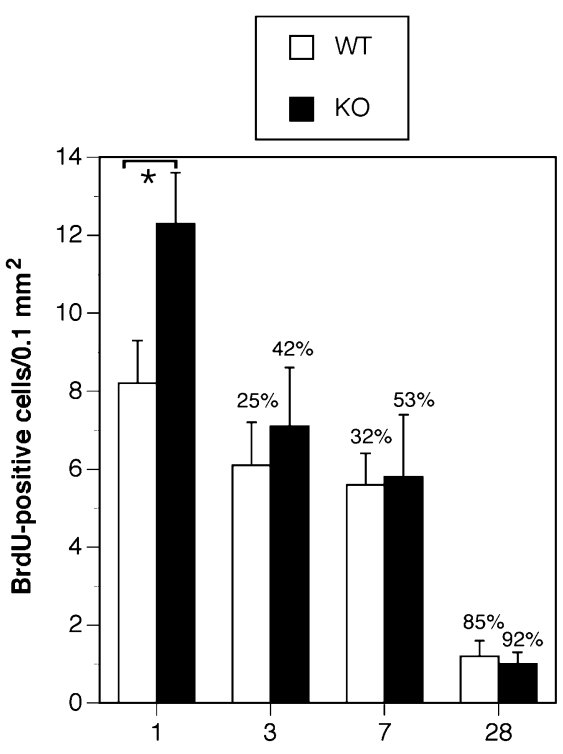

Days after last BrdU injection

Figure 9. The enriched subset of BrdU-labeled progenitors in $\mathrm{C} \times 32 \mathrm{KO}$ mice is deleted within $3 \mathrm{~d}$ of injection. Survival of BrdU + cells was assessed 1, 3, 7, and $28 \mathrm{~d}$ after the last BrdU injection. A statistically significant increase in BrdU-labeled cells in Cx32K0 dentate gyrus was detected $1 \mathrm{~d}$ after the last BrdU injection. Surviving cell number markedly decreased within $3 \mathrm{~d}$ of labeling in $\mathrm{C} \times 32 \mathrm{~K} 0$ dentate gyrus compared with WT. Percentage of reduction in cell number compared with day 1 is indicated at each time point. No difference in BrdU-labeled cell number between $\mathrm{C} \times 32 \mathrm{KO}$ and WT was detected $3(n=3), 7(n=3)$, and $28 \mathrm{~d}(n=5)$ after the last injection (ANOVA; post hoc Tukey test; ${ }^{*} p<0.05$ ).

Possible mechanisms underlying the defect in oligodendrogenesis in the $\mathrm{Cx} 32 \mathrm{KO}$ mouse

Although we have yet to identify the signals and associated transduction mechanisms responsible for the failure of a subset of early oligodendrocyte progenitors to differentiate in the absence of Cx32, two general mechanisms can be elaborated. The first uses orthodox junctional communication to transmit signals related to differentiation. The majority of gap junctions made by oligodendrocytes are with astrocytes and, to a lesser extent, with other oligodendrocytes (Massa and Mugnaimi, 1982; Wasman and Black, 1984; Li et al., 1997; Rash et al., 2001). Although this is the first study to localize Cx32 to oligodendrocyte progenitors, it is reasonable to assume that the same relationship will hold in other progenitor populations. Song et al. (2002) have provided elegant evidence that contact between progenitors and "instructive glia" in vitro can direct progenitor fate down specific lineages. GJIC may be one of the molecular mechanisms responsible for this control. Thus, in the absence of Cx32, affected early oligodendrocyte progenitors would be unable to interact with neighboring "instructive cells" and pass necessary second messengers required for further lineage progression.

A second possible mechanism involves the formation of hemichannels: connexin-based channels that are active in single plasma membranes. Cx26, $\mathrm{Cx} 32, \mathrm{Cx} 43$, and $\mathrm{Cx} 45$ are known to induce large, nonselective, voltage-gated conductances in single plasma membranes facilitating passage of metabolites and second messengers to and from extracellular space (Castro et al., 1999; Kammermans et al., 2001; Stout et al., 2002; Valiunas, 2002). These channels thereby provide a robust mechanism by which progenitors could sample and respond to changes in the extracellular environment in the absence of functional synapses and ligand-gated ion channels. This hypothesis represents an unexplored role for connexin-mediated hemichannels in vivo.
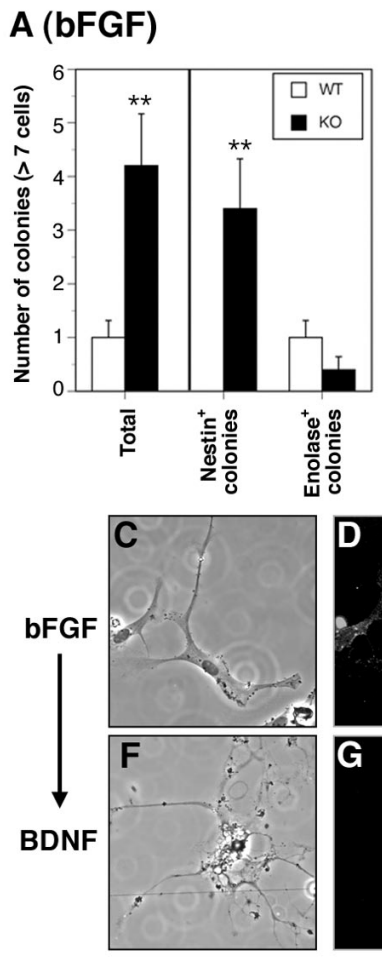

Phase
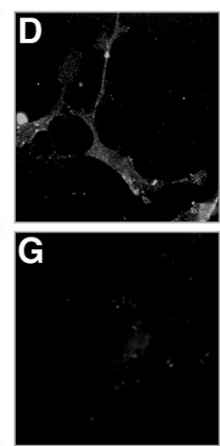

Nestin

\section{B (bFGF+BDNF)}
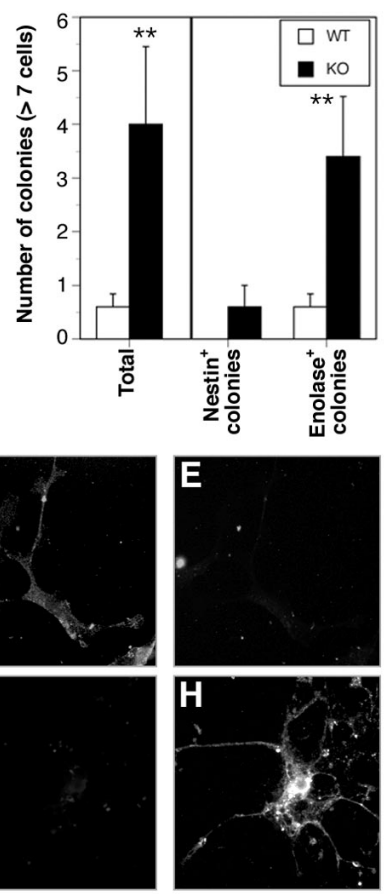

Enolase
Figure 10. More $\mathrm{C} \times 32 \mathrm{KO}$ progenitors cultured in vitro are capable of clonal expansion in the presence of bFGF and neuronal differentiation in the presence of BDNF than WT. A, Dissociated single cell suspensions prepared from the hippocampal formation of $n=3$ Cx32K0 and $n=3$ WT mice/experiment ( $n=3$ experiments) were plated on poly-o-lysine-coated glass microscope slides and cultured for $7 \mathrm{~d}$ in serum-free media containing $20 \mathrm{ng} / \mathrm{ml} \mathrm{bFGF}$, as described in Materials and Methods. Cultures were double-labeled for nestin (neural, glial, and early oligodendrocyte progenitor marker) or neuron-specific enolase (neuronal marker). Colonies (more than seven cells) were counted. Data are expressed as the mean number of colonies per well \pm SEM. A threefold increase in colony formation was detected in $\mathrm{KO}$ cultures (Total). Cells in $\mathrm{KO}$ colonies were nestin + indicative of progenitors (Nes$\mathrm{tin}^{+}$colonies). The rare WT colonies were enolase + indicative of terminally differentiated neurons (Enolase ${ }^{+}$colonies; ${ }^{* *} p<0.01$; Student's $t$ test). Single GFAP + cells were detected, but no GFAP + colonies were observed (data not shown). B, To determine whether the enriched population of nestin + progenitors could be differentiated to a neuronal phenotype, single cell suspensions were plated on poly-D-lysine-coated glass microscope slides and cultured for $7 \mathrm{~d}$ in serum-free media containing $20 \mathrm{ng} / \mathrm{ml} \mathrm{bFGF}$ followed by $5 \mathrm{~d}$ with media containing $10 \mathrm{ng} / \mathrm{ml}$ BDNF. A three-fold increase in colony formation was again detected in $\mathrm{C} 32 \mathrm{KO}$ cultures (Total). The majority of cells differentiated to a neuronal lineage (Enolase ${ }^{+}$colonies) after BDNF treatment. C, High-power magnification phase microscopy of KO cultures treated for $7 \mathrm{~d}$ with bFGF. D, E, Cells are nestin + and enolase-. $F$, High-power magnification phase microscopy of $K 0$ cultures treated for $7 \mathrm{~d}$ with bFGF followed by $5 \mathrm{~d}$ with BDNF. G, H, Cells are nestin - and enolase + with long neuritic extensions.

The current study localizes Cx32 to a subset of NG2+ and PDGF $\alpha \mathrm{R}+$ early oligodendrocyte progenitors as well as terminally differentiated oligodendroglia in the dentate gyrus of adult mice. In Cx32-deficient mice, we found that constitutive turnover of NG2+ progenitors is enhanced in the SGZ and polymorphonuclear layer of the dentate gyrus but that the progeny of these cells fail to terminally differentiate. These data provide empirical evidence to support the hypothesis that connexin expression influences adult progenitor number and specifically implicate Cx32-mediated signaling in the activation, survival, and differentiation of a subset of early oligodendrocyte progenitors in postnatal brain. 


\section{References}

Altevogt BM, Kleopas A, Postma FR, Scherer SS, Paul DL (2002) Connexin29 is uniquely distributed within myelinating glial cells of the central and peripheral nervous system. J Neurosci 22:6458-6470.

Anzini P, Neuberg DH, Schachner M, Nelles E, Willecke K, Zielasek J, Toyka KV, Suter B, Martini R (1997) Structural abnormalities and deficient maintenance of peripheral nerve myelin in mice lacking gap junction protein Connexin 32. J Neurosci 17:4545-4551.

Bahr M, Andres F, Timmerman V, Nelis ME, Van Broeckhoven C, Dichgans J (1999) Central visual, acoustic, and motor pathway involvement in a Charcot-Marie-Tooth family with an Asn205Ser mutation in the connexin 32 gene. J Neurol Neurosurg Psychiatry 66:202-206.

Bani-Yaghoub M, Underhill TM, Naus CC (1999) Gap junction blockage interferes with neuronal and astroglial differentiation of mouse P19 embryonal carcinoma cells. Dev Genet 24:69-81.

Belliveau DJ, Kidder GM, Naus CCG (1991) Expression of gap junction genes during postnatal neural development. Dev Genet 12:308-317.

Bennett SAL, Chen J, Pappas BA, Roberts DCS, Tenniswood M (1998) Alterations in platelet activating factor receptor expression associated with neuronal apoptosis in an in vivo model of excitotoxicity. Cell Death Differ 5:867-875.

Bennett SAL, Pappas BA, Stevens WD, Davidson CM, Fortin T, Chen J (2000) Cleavage of amyloid precursor protein elicited by chronic cerebral hypoperfusion. Neurobiol Aging 21:207-214.

Bergoffen J, Scherer SS, Wang S, Oronzi Scott M, Bone LJ, Paul DL, Chen K, Lensch MW, Chance PF, Fischbeck KH (1993) Connexin mutations in X-linked Charcot-Marie-Tooth disease. Science 262:2039-2042.

Bittman KS, LoTurco JJ (1999) Differential regulation of connexin 26 and 43 in murine neocortical precursors. Cereb Cortex 9:188-195.

Bittman K, Owens DF, Kriegstein AR, LoTurco JJ (1997) Cell coupling and uncoupling in the ventricular zone of the developing neocortex. J Neurosci 17:7037-7044

Bruzzone R, White TW, Scherer SS, Fischbeck KH, Paul DL (1994) Null mutations of connexin 32 in patients with X-linked Charcot-Marie-Tooth disease. Neuron 13:1253-1260.

Castro C, Gomez-Hernandez JM, Silander K, Barrio LC (1999) Altered formation of hemichannels and gap junction channels caused by $\mathrm{C}$-terminal connexin-32 mutations. J Neurosci 19:3752-3760.

Dawson MR, Levine JM, Reynolds R (2000) NG2-expressing cells in the central nervous system: Are they oligodendroglial progenitors? J Neurosci Res 61:479.

Dermietzel R, Traub O, Hwang TK, Beyer E, Bennett MVL, Spray DC (1989) Differential expression of three gap junction proteins in developing and mature brain tissues. Proc Natl Acad Sci USA 86:10148-10152.

Dermietzel R, Farooq M, Kessler JA, Althaus H, Hertzberg EL, Spray DC (1997) Oligodendrocytes express gap junction protein connexin32 and connexin45. Glia 20:101-114.

Fulton BP (1995) Gap junctions in the developing nervous system. Perspect Dev Neurobiol 12:327-334.

Gage FH (2000) Mammalian neural stem cells. Science 267:1433-1438.

Gallo V, Armstrong RC (1995) Developmental and growth factor-induced regulation of nestin in oligodendrocyte lineage cells. J Neurosci 15:394-406.

Guthrie SC, Gilula NB (1989) Gap junctional communication and development. Trends Neurosci 12:12-16.

Kammermans M, Fahrenfort I, Schultz K, Janssen-Bienhold U, Sjoerdsma T, Weiler R (2001) Hemichannel-mediated inhibition in the outer retina. Science 292:1178-1180.

Kempermann G, Kuhn HG, Gage FH (1997) Genetic influence on neurogenesis in the dentate gyrus of adult mice. Proc Natl Acad Sci USA 94:10409-10414.

Kondo T, Raff M (2000) Oligodendrocyte precursor cells reprogrammed to become multipotential stem cells. Science 289:1754-1757.

Lendahl U, Zimmerman LB, McKay RD (1990) CNS stem cells express a new class of intermediate filament protein. Cell 60:585-595.

Levine JM, Stincone F, Lee YS (1993) Development and differentiation of glial precursors of glial precursors. Glia 7:307-321.

Li J, Hertzberg EL, Nagy JI (1997) Connexin32 in oligodendrocytes and association with myelinated fibers in mouse and rat brain. J Comp Neurol 379:571-591.

Lo Turco JJ, Kriegstein AR (1991) Clusters of coupled neuroblasts in embryonic neocortex. Science 252:563-566.
Massa PT, Mugnaimi E (1982) Cell junctions and intramembrane particles of astrocytes and oligodendrocytes: a freeze-fracture study. Neuroscience 7:523-538.

Mercier F, Hatton GL (2001) Connexin 26 and basic fibroblast growth factor are expressed primarily in the subpial and subependymal layers in adult brain parenchyma: roles in stem cell proliferation and morphological plasticity? J Comp Neurol 431:88-104.

Nadarajah B, Jones AM, Evans WH, Parnavelas JG (1997) Differential expression of connexins during neocortical development and neuronal circuit formation. J Neurosci 17:3096-3111.

Nadarajah B, Makarenkova H, Becker DL, Evans WH, Parnavelas JG (1998) Basic FGF increases communication between cells of the developing neocortex. J Neurosci 18:7881-7890.

Nelles E, Buetzler C, Jung D, Temme A, Gabriel HD, Dahl U, Traub O, Stuempel F, Jungermann K, Zielasek J, Toyka KV, Dermietzel R, Willecke K (1996) Defective propagation of signals generated by sympathetic nerve stimulation in the liver of connexin32-deficient mice. Proc Natl Acad Sci USA 93:9565-9570.

Parnavelas JG, Luder R, Pollard SG, Sullivan K, Lieberman AR (1983) A qualitative and quantitative ultrastructural study of glial cells in the developing visual cortex. Philos Trans R Soc Lond B Biol Sci 10:103-114.

Pastor A, Kremer M, Moller T, Kettenmann H, Dermietzel R (1998) Dye coupling between spinal cord oligodendrocytes: differences in coupling efficiency between gray and white matter. Glia 24:108-120.

Rash JE, Yasumaura T, Dudek FE, Nagy JI (2001) Cell-specific expression of connexins and evidence of restricted gap junctional coupling between glial cells and between neurons. J Neurosci 21:183-2000.

Reynolds R, Hardy R (1997) Oligodendroglial progenitors labeled with the $\mathrm{O} 4$ antibody persist in the adult rat cerebral cortex in vivo. J Neurosci Res 47:455-470.

Rozental R, Morales M, Mehler MF, Urban M, Kremer M, Dermeitzel R, Kessler JA, Spray DC (1998) Changes in the properties of gap junctions during neuronal differentiation of hippocampal progenitor cells. J Neurosci 18:1753-1762.

Rozental R, Srinivas M, Gokhan S, Urban M, Dermietzel R, Kessler JA, Spray DC, Mehler MF (2000) Temporal expression of neuronal connexins during hippocampal ontogeny. Brain Res Brain Res Rev 32:57-71.

Scherer SS, Xu YT, Nelles E, Fischbeck K, Willecke K (1998) Connexin32null mutant mice develop demyelinating peripheral neuropathy. Glia 24:8-20.

Scherer SS, Deschenes SM, Xu Y, Grinspan JB, Fischbeck KH, Paul DL (1995) Connexin32 is a myelin-related protein in the PNS and CNS. J Neurosci 15:8281-8294.

Sohl G, Eiberger J, Jung YT, Kozak CA, Willecke K (2001) The mouse gap junction gene connexin29 is highly expressed in sciatic nerve and regulated during brain development. J Biol Chem 382:913-918.

Song H, Stevens CF, Gage FH (2002) Astroglia induce neurogenesis from adult neural stem cells. Nature 417:39-44.

Spassky N, Olivier C, Cobos I, LeBras B, Goujet-Zalc C, Martinez S, Zalc B, Thomas JL (2001) The early steps of oligodendrogenesis: insights from the study of the plp lineage in the brain of chicks and rodents. Dev Neurosci 23:318-326.

Stout CE, Costantin JL, Naus CC, Charles AC (2002) Intercellular calcium signaling in astrocytes via ATP release through connexin hemichannels. J Biol Chem 22:10482-10488.

Sutor B, Schmolke C, Teubner B, Schirmer C, Willecke K (2000) Myelination defects and neuronal hyperexcitability in the neocortex of connexin32deficient mice. Cereb Cortex 10:684-697.

Valiunas V (2002) Biophysical properties of connexin-45 gap junction hemichannels studies in vertebrate cells. J Gen Physiol 119:147-164.

Wasman SG, Black JA (1984) Freeze-fracture ultrastructure of the perinodal astrocyte and associated glial junctions. Brain Res 308:77-87.

Willecke K, Eiberger J, Degen J, Eckardt D, Romualdi A, Guldenagel M, Deutsch U, Sohl G (2001) Structural and functional diversity of connexin genes in the mouse and human genome. Biol Chem 383:725-737.

Williams BP, Park JP, Alberta JA, Muhlebach SG, Hwang GY, Roberts TM, Stiles CD (1997) A PDGF-regulated immediate early gene response initiates neuronal differentiation in ventricular zone progenitor cells. Neuron 18:553-562.

Yuste R, Nelson DA, Rubin WW, Katz LC (1995) Neuronal domains in developing neocortex: mechanisms of coactivation. Neuron 14:7-17. 